\title{
Training Needs Assessment for Practicing Paediatric Critical Care Nurses in Malawi To Inform The Development of A Specialized Master's Education Pathway: A Cohort Study
}

Kelsey Renning ( $\sim$ krenning@seedglobalhealth.org )

Seed Global Health

Brittney van de Water

Seed Global Health

Shelley Brandstetter

Seed Global Health

Chisomo Kasitomu

Queen Elizabeth Central Hospital

Netsayi Gowero

Kamuzu College of Nursing

Miriam Simbota

Kamuzu College of Nursing

Maureen Majamanda

Kamuzu College of Nursing

\section{Research Article}

Keywords: Critical care nursing, paediatric intensive care units, paediatrics, low resource setting, nursing education, global health nursing, nursing needs assessment

Posted Date: September 13th, 2021

DOl: https://doi.org/10.21203/rs.3.rs-730660/v1

License: (9) This work is licensed under a Creative Commons Attribution 4.0 International License. Read Full License 


\section{Abstract \\ Background}

Significant improvements in under-five mortality in Malawi have been demonstrated over the past thirty years; however, Malawian healthcare remains with gaps in availability and access to quality paediatric critical care nursing training and education. To improve expertise of paediatric critical care nurses in Malawi, Kamuzu College of Nursing (KCN), Queen Elizabeth Central Hospital (QECH), and Mercy James Center (MJC) entered a partnership with Seed Global Health, a US non-governmental organization. A needs assessment was conducted to understand the training needs of nurses currently working in paediatric critical care and in preparation for the development of a specialized Master's in Child Health pathway in Paediatric Critical Care (PCC) Nursing at KCN.

\section{Methods}

The needs assessment was completed using a survey questionnaire formatted using an ABCDE (Airway, Breathing, Circulation, Disability, and Exposure) framework. The questionnaire had Likert scale and yes/no questions. Data was manually entered into excel and was analyzed using descriptive statistics.

\section{Results}

One hundred and fifty-three nurses at QECH and MJC responded to the survey. Most nurses were between the ages of 25 and 35 years $(N=98,64 \%)$, female $(N=105,69 \%)$, and held either a Bachelors $(N=72$, $47 \%)$ or diploma ( $\mathrm{N}=70,46 \%)$ in nursing. Nurses had high rates of confidence in certain skills: airway management $(N=120,99 \%)$, breathing assessment \& management $(N=153,100 \%)$. However, nurses demonstrated little to no confidence in areas such as: mechanical ventilation ( $N=68,44 \%)$, ECG evaluation ( $=74,48 \%)$, and arterial blood gas collection \& interpretation $(N=49,32 \%)$.

\section{Conclusion}

It is important to identify priority areas for training and skills development to address in the PCC master's within the child health pathway at KCN. Ideally this partnership will produce practice-ready PCC nurses and will establish a recognized PCC nursing workforce in Malawi.

\section{Background:}

In 1990, Malawi had the second highest under-five mortality rate globally with 221 deaths per 1000 live births.[1] Significant improvements in under-five mortality in Malawi have been demonstrated over the past thirty years with recent data showing that the rate has declined to 41.6 deaths per 1000 live births.[2] Malawi is one of the few countries that met the Millennium Development Goal of reducing child mortality 
by two-thirds by 2015 due to improvements in childbirth and the prevention and treatment of diseases such as pneumonia, diarrhea, malaria, and HIV.[3] Following this accomplishment came the establishment of the agenda for 2030 Sustainable Development Goals (SDGs) which aim at further reducing deaths in the under-five population.[4] The Malawian Ministry of Health (MoH) highlights several strategies and programs aimed at improving health outcomes and access to care, including family planning, access to Skilled Birth Attendants, youth health services, and training health professionals in Helping Babies Breathe at all levels of healthcare from rural hospitals to district and central hospitals.[5]

Despite these encouraging statistics, Malawi remains with significant gaps in the availability of quality paediatric critical care and paediatric critical care nursing education and further progress must be made to achieve the health-related SDGs.[6, 7] One explanation for this gap may be the absence of specialized paediatric critical care training for nurses. It has been shown that level of training, length of nursing experience, and high nurse to patient ratios have been linked to mortality and adverse health outcomes in adult intensive care units, which presumably would be reflected in the paediatric realm.[8] Childbirth outside the hospital, financial constraints, and delayed presentation to the hospital due to lack of community-based healthcare negatively impact the survival of young children.[9-11] In Malawi, delay in care is often associated with parents providing home remedies to children and only going to the hospital when they perceive an illness to be life-threatening.[12] Consequently, critically ill children often arrive too late to the hospital for life-saving treatment, resulting in immediate (within four hours) or early (within 48 hours) death.[13]

To improve child mortality rates and better prepare nurses in Malawi, the researchers sought to perform a training needs assessment among practicing nurses in the paediatric units for critically ill children at Queen Elizabeth Central Hospital (QECH) and Mercy James Centre for Paediatric Surgery and Intensive Care (MJC) in Blantyre, Malawi. The findings from this assessment will help inform the development of a specialized Paediatric Critical Care (PCC) track within the Master's in Child Health Nursing Program at the Kamuzu College of Nursing (KCN).

\section{Partnership plan development}

$\mathrm{KCN}$ and QECH have been imparting clinical skills to nursing students in partnership since the opening of the nursing college in 1965. In the past decade, new initiatives have evolved at QECH with support from $\mathrm{KCN}$ child health members to address the burden of childhood illness, such as emergency care, High Dependency Unit (HDU) care, and nutritional rehabilitation. In 2017, with support from Raising Malawi and other stakeholders, QECH built the first paediatric critical care center in Malawi - MJC - comprised of a 6-bed paediatric intensive care unit (PICU), three operating theatres, HDUs, and a surgical ward.[14]

To improve nurses' expertise of paediatric critical care, KCN, QECH, and MJC entered a partnership with Seed Global Health (SGH), an American non-governmental organization.[15] From 2013-2018, KCN and SGH were connected through the Peace Corps' Global Health Service Partnership (GHSP) program. The 
goal of the current partnership is to create a pathway to a specialized PCC master's that would produce a formally recognized paediatric critical care nursing workforce by 2024 .

\section{Methods \\ Design}

A search for validated or published needs assessments for paediatric critical care nursing in low-resource settings returned no relevant results. Broadening the search to training needs assessments for paediatric critical care nursing in any setting returned only one validated tool, which lacked validation in other settings, was costly, and was deemed irrelevant for this project.[16] Therefore, the researchers developed a tool specifically for paediatric critical care nursing skills in Malawi.

A quantitative approach in the form of a questionnaire using an ABCDE framework with Likert-scale and yes/no questions was created. Additional questions asked about experience, current employment location, and future career aspirations to help illustrate any difference in learning needs. (See Appendix A: Needs Assessment Questionnaire).

No patients or members of the public were involved in the design, or conduct, or reporting, or dissemination plans of our research.

\section{ABCDE Framework}

Researchers developed a thorough, yet succinct, questionnaire covering specific components of critical care nursing using an "ABCDE" framework. This " $A B C D E$ " format is used in nursing assessment and documentation and includes assessment of Airway, Breathing, Circulation, Disability, and Exposure (ABCDE) domains.[17] Questions were based on expected PICU competencies covered during new nurse training at MJC and were focused on assessing knowledge and confidence in executing nursing skills. [18] To cover topics that are important in paediatric critical care nursing, yet not part of this ABCDE framework, thematic areas of infection prevention and family education were added. The questionnaire also included demographic, educational, and experiential items.

There were a total of three questions related to Airway, seven related to Breathing, fifteen related to Circulation, six related to Disability, and four related to Exposure. There were two questions related to Emergency Preparedness, three questions related to Infection Prevention, and one question related to Family Education. Each question had a Likert scale of 1-4 with 1 being "Not confident," 2 being "Somewhat confident" and 3 being "Confident" in that skill. A fourth option was "Unsure/I don't know."

\section{Setting and Population}

The training needs assessment questionnaire was distributed to 165 practicing nurses working in nine paediatric departments at QECH and MJC. The nine departments include: Paediatric Accident and Emergency $(N=20)$, Paediatric Special Care Ward HDU $(N=18)$, Paediatric Nursery HDU $(N=19)$, 
Nutritional Rehabilitation Unit HDU (N=8), Main ICU $(N=19)$, Neurology HDU $(N=13)$, Chatinkha Nursery $\operatorname{HDU}(\mathrm{N}=24)$, MJC HDU (N = 18), and MJC PICU ( $=26)$.

\section{Data Collection and Analysis}

The electronic questionnaire was distributed to nurses via email using Google Forms. Data were collected over two weeks and were entered into an excel spreadsheet for descriptive analysis.

\section{Results}

The questionnaire was completed by 153 practicing nurses (153/165, 92.7\% response rate). $77 \%$ of nurses were under the age of $35(\mathrm{~N}=118), 69 \%$ were female $(\mathrm{N}=105), 75 \%$ were permanent employees $(\mathrm{N}=115), 93 \%$ worked in paediatrics (142), 46\% held a diploma $(\mathrm{N}=70)$, and $47 \%$ held a bachelor's degree $(\mathrm{N}=72)$. The setting/specialty question was in multiple choice format; thus, the percentage of respondents does not add up to $100 \%$ reflecting nurses who work in multiple wards (Table 1).

\section{Airway}

Nurses were confident $(N=90,58.8 \%)$ or somewhat confident $(N=60,39.2 \%)$ in airway assessment and management. Specifically, nurses felt somewhat confident ( $N=55,35.9 \%)$ in endotracheal securing, monitoring, and management. However, 35 nurses (22.9\%) were not confident in this skill. Over threequarters of nurses felt confident in safe airway suctioning and nebulization $(\mathrm{N}=118,77.1 \%)$.

\section{Breathing}

Nurses were confident $(\mathrm{N}=136,88.9 \%)$ or somewhat confident $(\mathrm{N}=17,11.1 \%)$ in breathing assessment and management. Nurses were confident $(\mathrm{N}=62,40.5 \%)$ or somewhat confident $(\mathrm{N}=72,47.1 \%)$ in performing respiratory therapies. Many $(\mathrm{N}=68,44.4 \%)$ were somewhat confident in arterial blood gas collection, however there were nurses who were either confident $(N=36,23.5 \%)$ or not confident $(N=32$, $20.9 \%$ ). Results varied regarding use of mechanical ventilation equipment (modes, settings, troubleshooting) with an almost even split between nurses feeling confident $(N=37,24.2 \%)$, somewhat confident $(N=50,32.7 \%)$, and not confident $(N=45,30.1 \%)$. Nurses were similarly split when it came to care of a mechanically ventilated patient (monitoring, interpretation, care before and after extubating) and felt confident $(\mathrm{N}=48,31.4 \%)$, somewhat confident $(\mathrm{N}=37,24.2 \%)$, and not confident $(\mathrm{N}=46,30.1 \%)$. Most nurses felt confident $(N=93,60.8 \%)$ or somewhat confident $(N=37,24.2 \%)$ in use of bubble continuous positive airway pressure (bCPAP) equipment, patient monitoring, and troubleshooting.

\section{Circulation}

Most nurses ( $N=151,98.7 \%)$ were confident or somewhat confident in assessment of circulation. Nurses were somewhat confident ( $N=53,34.6 \%)$ or not confident $(N=46,30.1 \%)$ in electrocardiogram (ECG) evaluation, however some nurses did feel confident $(N=26,17 \%)$ or were unsure $(N=28,18.3 \%)$ of this skill. Less than half of nurses $(\mathrm{N}=69,45.1 \%)$ felt somewhat confident in performing a cardiac assessment, while other nurses felt confident $(N=36,23.5 \%)$ or not confident $(N=37,24.2 \%)$. Most 
nurses felt confident $(\mathrm{N}=52,34 \%)$ or somewhat confident $(\mathrm{N}=73,47.7 \%)$ in preparing and administering vasoactive medications (i.e., adrenaline), while some still felt not confident $(\mathrm{N}=22,14.4 \%)$. Regarding arterial line equipment, assessment, and interpretation, nurses were nearly evenly split between confident $(\mathrm{N}=37,24.2 \%)$, somewhat confident $(\mathrm{N}=48,31.4 \%)$, not confident $(\mathrm{N}=39,25.5 \%)$, and unsure $(\mathrm{N}=29$, $19 \%)$. Nurses were confident $(N=58,37.9 \%)$ or somewhat confident $(N=47,30.7 \%)$ in arterial line management (sample collection, dressing change, infection prevention, troubleshooting), while fewer were not confident $(\mathrm{N}=28,18.3 \%)$ or unsure $(\mathrm{N}=23,15 \%)$. Regarding knowledge of central line equipment, nurses were split between confident $(N=49,32 \%)$, somewhat confident $(N=48,31.4 \%)$, not confident $(N=32,20.9 \%)$, or unsure $(N=24,15.7 \%)$. Regarding central line management (sample collection, dressing change, infection prevention, troubleshooting), most nurses felt confident $(\mathrm{N}=62$, $40.5 \%)$ or somewhat confident $(\mathrm{N}=47,30.7 \%)$, however many still felt not confident $(\mathrm{N}=21,13.7 \%)$ or unsure $(\mathrm{N}=23,15 \%)$. Nurses $(\mathrm{N}=149,97.3 \%)$ felt confident or somewhat confident in peripheral IV management. Most nurses were somewhat confident $(N=51,33.3 \%)$, not confident $(N=64,41.8 \%)$, or unsure $(N=23,15 \%)$ about intraosseous cannula management, while only few nurses $(N=15,9.8 \%)$ were confident in this skill. Nurses felt somewhat confident $(\mathrm{N}=61,39.9 \%)$ in chest tube management. Others were split between confident $(N=35,22.9 \%)$, not confident $(N=38,24.8 \%)$, or unsure $(N=19,12.5 \%)$. Nurses overall were confident or somewhat confident in managing dehydration $(N=151,98.7 \%)$, fluid overload ( $N=150,98.1 \%)$, urinary catheters $(N=148,96.7 \%)$, and assessing urine output $(N=149,97.4 \%)$.

\section{Disability}

Nurses were confident or somewhat confident in neurological status assessment ( $N=145,94.8 \%)$, blood glucose monitoring $(N=150,98.1 \%)$, nasogastric tube management $(N=153,100 \%)$, total parenteral nutrition management $(N=130,84.9 \%)$, pain assessment $(N=149,97.4 \%)$. While most nurses felt confident $(N=48,31.4 \%)$ or somewhat confident $(N=70,45.8 \%)$ with sedation management, some nurses did not feel confident $(\mathrm{N}=26,17 \%)$.

\section{Exposure}

Nurses were confident or somewhat confident in management of hypothermia $(N=103,100 \%)$ and hyperthermia $(N=153,100 \%)$, skin integrity $(N=152,99.4 \%)$, and head-to-toe assessment $(N=148$, $96.8 \%)$.

\section{Emergency Preparedness, Infection Prevention, and Family Education}

Nurses were confident or somewhat confident in accessing emergency supplies ( $N=146,95.5 \%)$, recognizing a deteriorating child $(\mathrm{N}=150,98.1 \%)$, hand hygiene $(\mathrm{N}=152,99.3 \%)$, donning and doffing protective wear $(\mathrm{N}=152,99.3 \%)$, decontamination of equipment $(\mathrm{N}=150,98 \%)$, and providing family education ( $N=150,98.7 \%$ ) (see Table 2$)$.

\section{Work Environment}


Nurses were asked questions about the number of patients they work with and the equipment they use. Many nurses cared for either $1-3$ patients at a time $(N=56,36.6 \%)$ or greater than 17 patients $(N=38$, $24.8 \%$ ). Most nurses indicated that they do not have adequate equipment (bag valve masks, oxygen, bCPAP machines) $(N=124,81.1 \%)$ or supplies (gloves, aprons, masks, etc.) $(N=113,73.8 \%)$ required to perform essential job duties. However, most nurses indicated that the equipment they use does function properly $(\mathrm{N}=140,91.5 \%)$. Almost all nurses indicated that they are comfortable asking a colleague, supervisor $(N=152,99.3 \%)$, or medical doctor $(N=149,97.4 \%)$ questions about patient care (see Table 3).

Nurses were asked about their desire to stay in their current ward, desire to pursue a PCC master's, learning style, and past training. $76.5 \%$ of nurses $(\mathrm{N}=117)$ indicated a desire to remain in their current unit for five years or more, $88.9 \%(\mathrm{~N}=136)$ indicated a desire to pursue a PCC master's, and $80.4 \%(\mathrm{~N}=$ 123) prefer hands-on or simulation learning style. There were low rates of paediatric critical care training despite working in paediatric critical care areas. For example, only $65 \%$ of nurses had training in Emergency Triage, Assessment \& Treatment (ETAT), and 52\% had training in bCPAP. This question was written in multiple choice format, so some nurses may have indicated both ETAT and bCPAP training (see Table 1).

\section{Discussion}

Needs assessments alone are not enough to impact patient health outcomes, so this study is the beginning of a larger education and practice change.[19] Nurses with master's degrees have advanced nursing roles which enable them to provide clinical leadership, positively impact clinical practice, and improve the provision of care.[20] The findings indicate that only two participants were trained at the master's level, and these are principal and senior nursing officers. As such, their primary focus is on managerial and administrative duties rather than to provide bedside nursing care. This calls for more nurses to be trained at the master's level so that they can provide leadership in quality care of critically ill children.

Overall, there were high rates of critical care confidence among nurses. For example, nearly all nurses felt confident or somewhat confident in assessment and management of skills across all ABCDE domains. A study in Uganda and Zambia showed that healthcare providers' confidence increased with exposure to a variety of skills, which will be important to consider when designing the content of a PCC master's program.[21]

Nurses rated high confidence particularly in task-oriented or scale-dependent skills, including the Glasgow or Blantyre Coma Scale, blood glucose monitoring, nasogastric tube management, pain assessment, temperature monitoring, skin assessment, and infection prevention. Further investigation may be revealing as to whether nurses know how to interpret the data they collect, what intervention is indicated based on the findings, and when to reassess the patient, which would better demonstrate critical thinking skills and a higher level of nursing competency.[22] 
Although nearly $97 \%$ of nurses indicated "confident" or "somewhat confident" to performing head-to-toe assessments and focused cardiac and pulmonary assessments, nurses indicated lower levels of confidence in listening to heart sounds specifically. This may indicate a gap in nursing knowledge, incomplete or rushed assessments, or a lack of understanding of how to interpret assessment findings. Comprehensive head-to-toe and focused assessments are more meaningful if nurses can interpret the findings, anticipate interventions, make recommendations, and monitor a patient's response to the intervention because these actions help in identifying a patient whose condition is deteriorating. It will be important to identify the underlying cause of nurses' lack of confidence as a matter of patient safety.[23, 24]

High patient volumes could affect the nurses' ability to confidently perform assessments. Half the nurses care for 1-3 or 4-6 patients on a shift, which is comparable to some high-income settings such as California, USA, where state law requires a ratio of $1: 2$ for critical care wards and up to $1: 6$ in medical/surgical wards.[25] However, one third of nurses care for $>17$ patients and $75-80 \%$ of nurses feel their ward is understaffed and underequipped. While almost $100 \%$ of nurses feel comfortable asking a colleague, supervisor, or medical doctor a question about their patient's care, this still has great implications for the nurse's ability to dedicate quality time to individual patients, provide thorough education, and quickly recognize clinical deterioration.[26] High patient workload in paediatric critical care settings is associated with long hospital stays and poor health outcomes for patients, and for nurses, increased medical errors and burn out.[26-28]

Findings highlighted other areas where most of the nurses were less confident. Half the nurses were not confident or somewhat confident in managing endotracheal tubes or tracheostomies, and a little over half of nurses were not confident or somewhat confident in managing mechanical ventilation. This was not a surprising finding as the only ventilators are located at PICU at MJC and in the main ICU at QECH, therefore very few nurses provide care for ventilated patients. Additionally, intubation is not a skill that nurses are permitted to perform or gain competency in and so less familiarity with the procedure may impact confidence in managing related equipment such as endotracheal tubes and ventilators.[21]

Infrequent exposure may have also impacted nurses' low confidence in ECG interpretation despite nearly $90 \%$ confidence with cardiac assessments, as there is no dedicated paediatric cardiac unit and continuous ECG monitoring is not available on most of the paediatric units. Children with cardiac problems receive the same monitoring that other children receive: oxygen saturation, pulse rate, and temperature. Blood pressure and respirations are not routinely monitored in wards with high patient volume. Conversely, in the PICU at MJC, continuous monitoring is available, and the nurse-to-patient ratio is generally $1: 1$ or 1:2. Despite low confidence in ECG monitoring, most nurses $(\sim 80 \%)$ rated confident or somewhat confident their knowledge and use of vasoactive medications like adrenaline (used in cardiopulmonary resuscitation). When considering that many paediatric patients are very sick by the time they reach the hospital, the nurse's confidence in using such a medication could be reflected simply by its frequency of use. 
Considering effective learning styles for nurses, simulation has been shown to greatly impact nursing students' self-efficacy and performance of nursing skills.[29] When asked about learning preferences, $80 \%$ preferred hands-on simulation and nearly half of nurses were interested in e-learning technologies, while $68 \%$ reported bedside teaching and classroom learning were preferred. Furthermore, combining learning styles has been shown to improve nursing students' motivation, satisfaction, and subjectspecific knowledge when compared to online-only learning.[30] Providing varied and accessible learning modalities through simulation, flipped classroom, and online curriculum will be important for ensuring success among nursing students as the PCC pathway is being created.

Research suggests that nurse retention in Malawi is negatively impacted by poor compensation, poor working conditions, high patient ratios, unsupportive managerial relationships, lack of career advancement, and lack of performance evaluation.[31] It has conversely been shown that nurse retention in rural settings is positively impacted by a clear career pathway, mentorship, and financial incentives.[32] In Malawi specifically there are strong religious and patriotic factors that increase retention.[31] Supportive work environments increase nurses' job satisfaction, but have the added benefit of positively affecting patient and family satisfaction.[33,34] Encouragingly, $76.5 \%$ of nurses had a desire to stay in their current ward for five years or more, and $89 \%$ of nurses were interested in pursuing a PCC master's degree (if funding were attainable). These findings may represent protective factors positively impacting nurse retention rates and a desire for specialization. Creating a PCC master's pathway will give nurses an opportunity to acquire specialized skills which would encourage the $\mathrm{MoH}$ and hospital leadership to allow nurses to work within their area of expertise, improving nurses' job satisfaction and ultimately patient care.

\section{Limitations}

This study is not without limitations. While English is the official language of Malawi, it is commonly nurses' second language which could contribute to some measurement error. This study was conducted at one tertiary facility. Our tool was not validated; therefore, we cannot be certain that this is truly measuring nurses' confidence. The nurses work in a wide range of wards, and due to the inability to complete a comparative analysis, we are unable to determine the differences in responses by nurses from ward to ward. Although the questionnaire was considered confidential, data was deidentified for analysis, and answers were not shared with clinical department heads (eliminating the risk of repercussions for low-confidence responses), nurses may have reported over-confidence in their skills due to an inherent desire to prove clinical competence and adhere to unit standards. Additionally, we must recognize that self-rated confidence may not transfer to validated competence and improved patient outcomes.

\section{Conclusion}

Among 153 practicing nurses we found that nurses indicated a high level of confidence across all ABCDE domains and in task or scale-dependent skills like NG tube management, pain assessment, and coma scores. We were able to better understand nurses' training needs related to paediatric critical care; most 
gaps were in mechanical ventilation, ECG evaluation and cardiac assessment, intraosseous cannulation, and chest tube management. Confidence in some skills was variable, possibly dependent on frequency of exposure to that skill. Findings demonstrated a possible knowledge gap between performing assessments and interpreting assessment findings. High patient volume could be impacting confidence in assessments. Concerns regarding poor staffing and inadequate equipment were also highlighted.

The nurses' responses have illuminated themes that occur commonly in low-resource settings, and therefore these findings could be generalized to benefit similar low-resource settings around the world. In Malawi, this study will contribute to the development of a PCC master's pathway. It will be important to involve the Ministry of Education and $\mathrm{MoH}$ in the planning of this program to best employ nurses and to better serve the children in need of high acuity nursing care.

\section{Declarations}

\section{Acknowledgements}

We are grateful to SGH for the financial support. We are thankful to the nurses who participated in the questionnaire and the management of $\mathrm{KCN}$ and $\mathrm{QECH}$ for allowing us to conduct this study.

\section{Dissemination Declaration}

The results of this study will be disseminated to the study participants as well as relevant clinical partners.

\section{Corresponding Author Statement}

The Corresponding Author has the right to grant on behalf of all authors and does grant on behalf of all authors, an exclusive license (or non-exclusive for government employees) on a worldwide basis to the BMJ Publishing Group Ltd to permit this article (if accepted) to be published in BMJ editions and any other BMJPGL products and sublicences such use and exploit all subsidiary rights, as set out in our license. The Corresponding Author attests that all listed authors meet authorship criteria and that no others meeting the criteria have been omitted.

\section{Authors' Contributions}

$\mathrm{SB}, \mathrm{BvdW}, \mathrm{CK}, \mathrm{MM}$, and MS were involved in the concept and design, and development of the protocol and analysis plan. Acquisition of data was completed by NG. KR and BvdW completed the data analysis. $\mathrm{KR}$ drafted the manuscript. All authors contributed to the study design and revision of the manuscript. The corresponding author attests that all authors meet authorship criteria and no others meeting the criteria have been omitted.

\section{Competing Interest Statement}


All authors have completed the Unified Competing Interest form (available on request from the corresponding author) and declare: no support from any organization for the submitted work; no financial relationships with any organizations that might have an interest in the submitted work in the previous three years, no other relationships or activities that could appear to have influenced the submitted work.

\section{Transparency Declaration}

I, the manuscript's guarantor, affirm that the manuscript is an honest, accurate, and transparent account of the study being reported; that no important aspects of the study have been omitted; and that any discrepancies from the study as planned have been explained.

\section{Ethical Approval and Consent to Participate}

Approval for this study was obtained by the College of Medicine Research Ethics Committee (P.03/20/2986) through the University of Malawi College of Medicine. Consent for this study was obtained from QECH management including the hospital director, paediatric clinical and academic directors, and the head of MJC. Written consent was obtained electronically via Google Forms by each participant prior to completion of the survey. Participation was voluntary and responses to the questionnaire were confidential. All methods were performed in accordance with the relevant guidelines and regulations.

\section{Consent for Publication}

Not applicable.

\section{Funding}

Funding was provided directly by SGH. No official grant number was awarded. SGH did not play a role in the study design, collection, analysis, and interpretation of data, writing of the manuscript, or the decision to submit the article for publication. All authors, external and internal, had access to all the data in this study and can take responsibility for the integrity and accuracy of the data and its analysis.

\section{Data Sharing Statement}

No additional data. The data that support the findings of this study are available from the corresponding author, $\mathrm{KR}$, upon reasonable request.

\section{Author License Statement}

I, the Submitting Author has the right to grant and does grant on behalf of all authors of the Work (as defined in the author license), an exclusive license and/or a non-exclusive license for contributions from authors who are: i) UK Crown employees; ii) where BMJ has agreed a CC-BY license shall apply, and/or iii) in accordance with the terms applicable for US Federal Government officers or employees acting as part 
of their official duties; on a worldwide, perpetual, irrevocable, royalty-free basis to BMJ Publishing Group Ltd ("BMJ") its licensees.

The Submitting Author accepts and understands that any supply made under these terms is made by BMJ to the Submitting Author unless you are acting as an employee on behalf of your employer or a postgraduate student of an affiliated institution which is paying any applicable article publishing charge ("APC") for Open Access articles. Where the Submitting Author wishes to make the Work available on an Open Access basis (and intends to pay the relevant APC), the terms of reuse of such Open Access shall be governed by a Creative Commons license - details of these licenses and which license will apply to this Work are set out in our license referred to above.

\section{References}

1. Jahn A, Floyd S, Crampin AC et al. Declining child mortality in northern Malawi despite high rates of infection with HIV. Bull World Health Organ. 2010;88(10):746-53.

2. Malawi (MWI) - demographics, health \& infant mortality - UNICEF DATA [Internet]. Unicef.org. 2020 [cited 2021 Jun 19]. Available from: https://data.unicef.org/country/mwi/

3. Kanyuka M, Ndawala J, Mleme T et al. Malawi and Millennium Development Goal 4: a Countdown to 2015 country case study. The Lancet Global Health 2016;4. doi:10.1016/s2214-109x(15)00294-6

4. Health and population [Internet]. Sdgs.un.org. [cited 2021 Jun 19]. Available from: https://sdgs.un.org/topics/health-and-population

5. Gov.mw. [cited 2021 Jun 19]. Available from: https://www.health.gov.mw/index.php/maternalneonatal-care

6. Malawi 2020 Voluntary National Review Report for Sustainable Development Goals [Internet]. Malawi.un.org. [cited 2021 Jun 19]. Available from: https://malawi.un.org/en/52003-malawi-2020voluntary-national-review-report-sustainable-development-goals

7. Zere $\mathrm{E}$, Moeti M, Kirigia $\mathrm{J}$ et al. Equity in health and healthcare in Malawi: analysis of trends. BMC Public Health. 2007;7(1):78.

8. West E, Mays N, Rafferty AM et al. Nursing resources and patient outcomes in intensive care: a systematic review of the literature. Int J Nurs Stud. 2009;46(7):993-1011.

9. Ameh EA, Seyi-Olajide JO, Sholadoye TT. Neonatal surgical care: a review of the burden, progress and challenges in sub-Saharan Africa. Paediatr Int Child Health. 2015;35(3):243-51.

10. Osifo DO, Oriaifo IA. Factors affecting the management and outcome of neonatal surgery in Benin City, Nigeria. Eur J Pediatr Surg. 2008;18(2):107-10.

11. Rose AM. Late presentation to hospital services necessitates greater community-based care for malnourished children. J Trop Pediatr. 2015;61(1):61-4.

12. Desmond NA, Nyirenda D, Dube $Q$ et al. Recognising and treatment seeking for acute bacterial meningitis in adults and children in resource-poor settings: A qualitative study. PLoS One. 2013;8(7):e68163. 
13. Berkley JA, Ross A, Mwangi I et al. Prognostic indicators of early and late death in children admitted to district hospital in Kenya: cohort study. BMJ. 2003;326(7385):361.

14. Our work - raising Malawi [Internet]. Raisingmalawi.org. [cited 2021 Jun 19]. Available from: https://www.raisingmalawi.org/our-work

15. Home [Internet]. Seedglobalhealth.org. 2014 [cited 2021 Jun 19]. Available from: https://seedglobalhealth.org

16. Long D, Young J, Rickard CM et al. Measuring paediatric intensive care nursing knowledge in Australia and New Zealand: how the Basic Knowledge Assessment Tool for pediatric critical care nurses (PEDS-BKAT4) performs. Aust Crit Care. 2013;26(1):36-42.

17. Thim T, Krarup NHV, Grove EL et al. Initial assessment and treatment with the Airway, Breathing, Circulation, Disability, Exposure (ABCDE) approach. Int J Gen Med. 2012;5:117-21.

18. Needs Assessment, Gap I a. Needs assessment and identifying a gap in knowledge, skills and/or practices [Internet]. Ymaws.com. [cited 2021 Jun 19]. Available from: https://cdn.ymaws.com/www.oregonrn.org/resource/resmgr/OCEAN/OCEAN_ANCC-GapAssess.pdf

19. Grant J. Learning needs assessment: assessing the need. BMJ. 2002;324(7330):156-9.

20. Begley C, Elliott N, Lalor J et al. Differences between clinical specialist and advanced practitioner clinical practice, leadership, and research roles, responsibilities, and perceived outcomes (the SCAPE study). J Adv Nurs. 2013;69(6):1323-37.

21. Kim MK, Arsenault C, Atuyambe LM et al. Determinants of healthcare providers' confidence in their clinical skills to deliver quality obstetric and newborn care in Uganda and Zambia. BMC Health Serv Res. 2020;20(1):539.

22. Chang MJ, Chang Y-J, Kuo S-H et al. Relationships between critical thinking ability and nursing competence in clinical nurses: Predictors of nursing competence. J Clin Nurs. 2011;20(2122):3224-32.

23. Jones MB, Tucker D. Nursing considerations in pediatric cardiac critical care. Pediatr Crit Care Med. 2016;17:S383-7.

24. Tucker $D$, Hazinski MF. The nursing perspective on monitoring hemodynamics and oxygen transport. Pediatr Crit Care Med. 2011;12(4 Suppl):S72-5.

25. The importance of the optimal nurse-to-patient ratio [Internet]. Wolterskluwer.com. 2016 [cited 2021 Jun 19]. Available from: https://www.wolterskluwer.com/en/expert-insights/the-importance-of-theoptimal-nursetopatient-ratio

26. Wheeler DS, Dewan M, Maxwell A et al. Staffing and workforce issues in the pediatric intensive care unit. Transl Pediatr. 2018;7(4):275-83.

27. Diehl $E$, Rieger $S$, Letzel $S$ et al. The relationship between workload and burnout among nurses: The buffering role of personal, social and organisational resources. PLoS One. 2021;16(1):e0245798.

28. Fundora MP, Liu J, Calamaro $\mathrm{C}$ et al. The association of workload and outcomes in the pediatric cardiac ICU. Pediatr Crit Care Med [Internet]. 2021; Available from: 
http://dx.doi.org/10.1097/PCC.0000000000002740

29. Lin H-H. Effectiveness of simulation-based learning on student nurses' self-efficacy and performance while learning fundamental nursing skills. Technol Health Care. 2015;24 Suppl 1(s1):S369-75.

30. McCutcheon K, O'Halloran P, Lohan M. Online learning versus blended learning of clinical supervisee skills with pre-registration nursing students: A randomised controlled trial. Int J Nurs Stud. 2018;82:30-9.

31. Grigulis Al, Prost A, Osrin D. The lives of Malawian nurses: the stories behind the statistics. Trans R Soc Trop Med Hyg. 2009;103(12):1195-6.

32. Mbemba G, Gagnon M-P, Paré G et al. Interventions for supporting nurse retention in rural and remote areas: an umbrella review. Hum Resour Health. 2013;11(1):44.

33. Hayhurst A, Saylor C, Stuenkel D. Work environmental factors and retention of nurses. J Nurs Care Qual. 2005;20(3):283-8.

34. Tzeng H-M, Ketefian S, Redman RW. Relationship of nurses' assessment of organizational culture, job satisfaction, and patient satisfaction with nursing care. Int J Nurs Stud. 2002;39(1):79-84.

\section{Tables}

Due to technical limitations, table $1,2,3$ is only available as a download in the Supplemental Files section.

\section{Supplementary Files}

This is a list of supplementary files associated with this preprint. Click to download.

- Table1a.jpg

- Table1b.jpg

- Table1c.jpg

- Table2a.jpg

- Table2b.jpg

- Table3.jpg

- Appendix.docx 